\title{
A extensão universitária como agente transformadora da sociedade: estudo de caso da Biblioteca Comunitária do bairro Saramenha de Cima - Ouro Preto/MG
}

The university extension as an agent for social transformation: a case study of the Community

\author{
Library of Saramenha de Cima neighborhood - Ouro Preto/MG
}

La extensión universitaria como agente transformador de la sociedad: un estudio de caso de la Biblioteca Comunitaria en el barrio Saramenha de Cima - Ouro Preto / MG

\author{
Thiago Duarte Figueiredo \\ ORCID: https://orcid.org/0000-0001-6885-465X \\ Universidade Federal de Ouro Preto, Brasil \\ E-mail: thiago.df@aluno.ufop.edu.br \\ Caio Cesar Gonzaga Alves \\ ORCID: https://orcid.org/0000-0002-0520-2176 \\ Universidade Federal de Ouro Preto, Brasil \\ E-mail: caio.alves1@aluno.ufop.edu.br \\ Crislaine Souza \\ ORCID: https://orcid.org/0000-0002-6259-4698 \\ Universidade Federal de Ouro Preto, Brasil \\ E-mail: crislaine19souza@gmail.com \\ Guilherme Henrique Gualandi Rodrigues \\ ORCID: https://orcid.org/0000-0003-0483-3694 \\ Universidade Federal de Ouro Preto, Brasil \\ E-mail: guilhermegualandi@hotmail.com \\ Carlos Alberto Pereira \\ ORCID: https://orcid.org/0000-0003-0510-0257 \\ Universidade Federal de Ouro Preto, Brasil \\ E-mail: pereiraufop@gmail.com
}

\begin{abstract}
Resumo
As bibliotecas comunitárias são ambientes sociais criados pela própria comunidade para promover acesso à informação e lazer à população local. Esses ambientes se tornam importantes pontos de apoio, reduzindo desigualdades sociais e garantindo o desenvolvimento pedagógico e cultural. Nesse contexto, no ano de 2005, foi criada a Biblioteca Comunitária de Saramenha de Cima, no bairro de mesmo nome na cidade de Ouro Preto-MG, numa parceria entre grupos locais e Universidade Federal de Ouro Preto (UFOP). A biblioteca promove atividades de estímulo à leitura, oficinas, reforço escolar e empréstimos de livros, com participação de alunos de extensão universitária dos cursos de graduação da UFOP nas atividades do projeto. Esse artigo avalia o impacto da Biblioteca Comunitária de Saramenha de Cima na melhoria da educação e qualidade de vida da população local, por meio de levantamento de dados de desempenho escolar das crianças participantes, análises dos principais pontos de transformação do projeto na comunidade e no desenvolvimento pessoal e acadêmico dos extensionistas. O estudo destacou como o projeto trouxe o sentimento de orgulho e pertencimento à população local, se tornando ponto de lazer, cultura e, principalmente, desenvolvimento educacional, com a escola do bairro obtendo crescente rendimento acadêmico com apoio da biblioteca, obtendo resultados superiores as médias municipal, estadual e nacional. Além disso, o projeto promove a aproximação entre a comunidade e a universidade, garantindo também um amadurecimento pessoal importantíssimo aos extensionistas participantes, preparando os no âmbito acadêmico, com apresentação de trabalhos relacionados e tornando-os mais humanos e melhor preparados para o futuro.
\end{abstract}

Palavras-chave: Biblioteca comunitária; Ação social; Extensão universitária; Educação.

\begin{abstract}
Community libraries are social environments created by the community to promote access to information and leisure for the local population. These environments become important support points, reducing social inequalities and guaranteeing pedagogical and cultural development. In this context, in 2005, the Community Library of Saramenha de Cima was created, in the neighborhood of the same name in the city of Ouro Preto-MG, in a partnership between local groups and the Federal University of Ouro Preto (UFOP). The library promotes activities to encourage reading, workshops, tutoring and book lending, with the participation in the project's activities of university extension students from UFOP's undergraduate courses. This article assesses the impact of the Saramenha de Cima Community Library in improving the education and quality of life of the local population, through a survey of school performance data of
\end{abstract}


participating children, analysis of the main points of transformation in the community and in personal development, and academic extension workers. The study highlighted how the project brought the feeling of pride and belonging to the local population, becoming a point of leisure, culture and, above all, educational development, with the neighborhood school achieving educational growth with the support of the library, obtaining superior results such as academic performance municipal, state and national. In addition, the project promotes a rapprochement between the community and the university, also ensuring a very important personal maturity to the participating extension workers, preparing academics, presenting related works and making them more human and better prepared for the future.

Keywords: Community library; Social action; University extension; Education.

\section{Resumen}

Las bibliotecas comunitarias son entornos sociales creados por la comunidad para promover el acceso a la información y el esparcimiento de la población local. Estos entornos se convierten en importantes puntos de apoyo, mitigación de la desigualdad social y garantía del desarrollo pedagógico y cultural. En este contexto, en 2005 se creó la Biblioteca Comunitaria de Saramenha de Cima, en el barrio del mismo nombre en la ciudad de Ouro Preto-MG, en alianza entre grupos locales y la Universidad Federal de Ouro Preto (UFOP). La biblioteca promueve actividades de fomento de la lectura, talleres, tutorías y préstamo de libros, con la participación de estudiantes de extensión universitaria de los cursos de pregrado de la UFOP en las actividades del proyecto. Este artículo evalúa el impacto de la Biblioteca Comunitaria Saramenha de Cima en la mejora de la educación y la calidad de vida de la población local, a través de una encuesta de datos de desempeño escolar de los niños participantes, análisis de los principales puntos de transformación en la comunidad y en el desarrollo personal. y extensionistas académicos. El estudio destacó cómo el proyecto trajo el sentimiento de orgullo y pertenencia a la población local, convirtiéndose en un punto de ocio, cultura y, sobre todo, desarrollo educativo, con la escuela del barrio logrando un crecimiento educativo con el apoyo de la biblioteca, obteniendo resultados superiores. como el rendimiento académico municipal, estatal y nacional. Además, el proyecto promueve un acercamiento entre la comunidad y la universidad, asegurando también una madurez personal muy importante a los extensionistas participantes, preparando académicos, presentando trabajos afines y haciéndolos más humanos y mejor preparados para el futuro.

Palabras clave: Biblioteca comunitaria; Acción social; Extensión universitaria; Educación.

\section{Introdução}

O conceito de Extensão Universitária tem início no século XIX, na Inglaterra, tendo como propósito direcionar novos caminhos para a sociedade e promover a educação continuada. Desde então, o projeto de extensão é visto como parte do processo acadêmico universitário, definido e efetivado em função das exigências da realidade (Rodrigues et al., 2013). De acordo com a Política Nacional de Extensão Universitária (Forproex, 2012), a prática de atividades extensionistas no Brasil remonta ao início do século XX, definida como ferramenta atuante no seio da luta pela redemocratização e reconstrução das instituições de políticas públicas e sociais dentro do território brasileiro. Assim, para minimizar as defasagens culturais, informacionais e sociais enfrentadas pela população periférica brasileira, foram desenvolvidas ferramentas de intervenção como as bibliotecas comunitárias.

Conforme Almeida Junior (1997) as bibliotecas públicas, instituições apoiadas pelo governo se encontram predominantemente inseridas nas regiões centrais das cidades, privilegiando, indiretamente, os habitantes já com maior acesso à cultura, informação e educação de qualidade. Com isso, a dificuldade da população periférica das cidades e habitantes da zona rural em frequentar tais espaços promove a exclusão dessa parcela da sociedade ao acesso à informação (Suaiden, 1995), de forma que as bibliotecas comunitárias se tornam uma das únicas ferramentas de mudança desse cenário.

Segundo Silva e Sousa (2010), as bibliotecas comunitárias, se encontram geralmente, em regiões periféricas ou com pouco acesso à informação por parte da população local sendo criadas e geridas por membros da própria comunidade como meio de combate à desigualdade social e exclusão educacional e de democratização do conhecimento, se tornando uma ferramenta de auxílio para suprir a ausência de bibliotecas públicas nas periferias e regiões carentes. Dessa forma, as bibliotecas comunitárias vêm se destacando como espaços de democratização social e cultural, promovendo a disseminação da informação e da cultura, e, por serem criadas pela própria comunidade, apresentam características específicas para o atendimento das principais necessidades locais, garantindo a aceitação e participação ativa da população no projeto (Flusser, 
1980). Para Machado e Vergueiro (2010), esses espaços são ambientes estratégicos para a implantação de políticas sociais, por parcerias com instituições de ensino ou grupos locais, estreitando a relação entre o projeto e a comunidade, possibilitando uma atuação mais assertiva.

Nesse contexto, em 2001, a Universidade Federal de Ouro Preto (UFOP) em consonância com a Prefeitura local e com a Associação de Bairro do Morro Sebastião, contando com subsídios do Programa de Educação da empresa Novelis S.A., implantaram a primeira biblioteca comunitária da região ouro-pretana "Biblioteca Comunitária Professora Altina Catarina da Conceição Pereira", sediada no bairro Morro do São Sebastião como parte do projeto Oficina da Ciência e Cidadania, para promover o estímulo à leitura nas áreas periféricas da cidade (Pires et al., 2016). Atuando como um projeto de extensão universitária, o projeto foi de grande importância para a comunidade local e para os alunos extensionistas atuantes.

Devido aos resultados positivos oriundos dessa fundação, em 2005, foi criada a segunda biblioteca comunitária da cidade de Ouro Preto, localizada no bairro Saramenha de Cima a fim de promover a pluralização do direito ao acesso à informação, literatura e lazer. Desde então, o projeto estrutura-se para despertar o interesse da comunidade para o aprendizado do exercício da ciência e autoconfiança, ampliando as oportunidades de estudo entre crianças, jovens e adultos, suprindo a defasagem do aprendizado formal dos frequentadores da localidade e fomentando o desenvolvimento da cidadania em sua verdadeira forma, permitindo aos participantes se reconhecerem como cidadãos, suas funções, direitos e enfim serem capazes de entender seus deveres e reivindicar suas necessidades perante a sociedade (Targino, 1991).

Como evidenciam Fernandez, Machado e Rosa (2018), as bibliotecas comunitárias apresentam como característica organizacional uma gestão compartilhada, formada pelos idealizadores do projeto, coordenadores, e demais apoiadores, atuando como conselho consultivo ou deliberativo. Atualmente, o grupo gestor da nova biblioteca é formado por representantes e bolsistas do Instituto Federal de Minas Gerais (IFMG) - Campus Ouro Preto em conjunto com alunos extensionistas da Universidade Federal de Ouro Preto e apoiadores locais, como a Escola Municipal René Gianetti, associações de bairro e a Igreja São José. Mediante essa junção de auxiliares, foi possível adquirir um espaço de boa infraestrutura para o prosseguimento do projeto, com o cadastro no programa de bibliotecas comunitárias da Fundação Biblioteca Nacional e recebimento de quatrocentos novos livros, agregando ao acervo, que está em constante evolução.

Quanto à programação, a biblioteca funciona de segunda a sexta feira, com atividades ministradas por três extensionistas, um mestrando de engenharia e voluntários da comunidade. O processo seletivo dos alunos extensionistas da UFOP para atuar no projeto leva em consideração a disponibilidade de carga horária e valor do coeficiente de rendimento do graduando. Geralmente, é exigida a disponibilidade de 15 horas semanais para bolsistas credenciados pela universidade e 20 horas semanais para os patrocinados por outras instituições - ambos devem apresentar coeficiente de rendimento igual ou superior a seis. A divulgação das vagas, às quais qualquer aluno da universidade, independente do curso, pode manifestar interesse e participar da seleção, são realizadas por meio de veículos midiáticos como as redes sociais.

Assim como Paulo Freire (2008, p. 33) relaciona o conceito de biblioteca a "[...] um centro cultural e não como um depósito silencioso de livros", Machado e Vergueiro (2010), indicam a importância e o potencial das bibliotecas comunitárias no desenvolvimento de ações culturais, consistindo em ferramentas para o desenvolvimento da comunidade, potencializando os talentos locais e utilizando seu espaço para iniciativas inovadoras, propositivas e criativas. Desse modo, além da prática histórica e rotineira de empréstimos de livros, foram desenvolvidas ações didático-pedagógicas nas mediações do espaço, que são discutidas e planejadas em reuniões mensais por equipes de trabalho formadas por coordenadores e atuais bolsistas da unidade. Por conseguinte, as metodologias ali executadas são voltadas para o desenvolvimento intelectual, social e cultural dos indivíduos, abrangendo atividades como:

a) Reforço escolar: "[...] o segredo de um bom ensino é respeitar a inteligência da criança como um campo fértil onde as sementes devem ser semeadas, para crescerem no calor da imaginação flamejante.” (Montessori, 2006, p. 20). O reforço 
escolar é monitorado por duas bolsistas que auxiliam os estudantes nas tarefas extraclasse, pesquisas e trabalhos ao longo da semana. Essa é uma rotina que, apesar de parecer simples, exige muita atenção dos extensionistas para que os alunos obtenham, mediante orientação, não apenas a resolução de seus deveres escolares, mas também o estímulo necessário para os fazer sozinhos.

b) Clube da leitura: de acordo com a Tertúlia Literária Dialógica da Escola de Educação de Pessoas Adultas de La Verneda de Sant Marti em Barcelona/Espanha, e em desenvolvimento no Brasil pelo Núcleo de Investigação de São Carlos, a prática da leitura é baseada na interlocução, não possuindo um objetivo direto de descobrir nem analisar aquilo que o autor ou autora de uma determinada obra quer dizer em seus textos, mas de promover uma reflexão a partir das diferentes e possíveis interpretações que derivam destes (Batel et al., 2003). Nesse sentido, as metodologias aplicadas no "Clube da Leitura" buscam a interação dialética mútua entre os bolsistas e as crianças, trabalhando no desenvolvimento da análise crítica textual e habituação da leitura. Essa espécie de leitura dinamizada, de caráter cultural e pedagógico, é ministrada para abranger faixas etárias de 5 a 15 anos e é praticada gratuitamente todas as segundas-feiras nas mediações da Biblioteca Comunitária Saramenha de Cima, baseando-se na escolha de uma obra específica para leitura por parte das crianças seguida pela discussão sobre a história lida e reflexão dos pontos levantados pelos alunos, incentivando o desenvolvimento da leitura, da argumentação e do raciocínio descritivo.

c) Aulas de inglês: as atividades realizadas pelo projeto visam também à qualificação dos seus participantes em relação ao futuro. Diante disso, o ensino do inglês torna-se essencial. Atualmente, as aulas de inglês são ministradas, por duas bolsistas, duas vezes por semana, segunda e quarta-feira, com a duração de 50 minutos cada aula. Esse trabalho é realizado com crianças de cinco a nove anos que se encontram no nível básico de inglês, introduzido por meio de atividades pedagógicas que envolvem memorização de palavras por meio de ilustrações a fim de facilitar e enriquecer o conteúdo ali ensinado.

d) Recreação, oficinas e passeios: assim como é afirmado pelo pensador norte-americano Dewey (1940) que somente no âmbito natural da criança ela poderá ter um desenvolvimento didático-pedagógico seguro, sabe-se que o jogo faz parte desse ambiente natural e por meio dele podem-se desenvolver atividades culto-pedagógicas que estimulam o poder criativo, inquisidor e participativo da criança no meio em que habita. Nesse contexto, foram dispostos para todos os frequentadores da biblioteca dois computadores com jogos de raciocínio matemático e digitação, além da disponibilidade das máquinas para estudos, pesquisas e a habituação das crianças com novas tecnologias, que, como ressaltam Batista et al. (2019), são ferramentas fundamentais de aproximação dos alunos com realidades até então distantes, ampliando as oportunidades de conhecimento. Além disso, são disponibilizados na biblioteca comunitária brinquedos, e a deliberação de uma quadra poliesportiva da comunidade para práticas de lazer. Atividades de criação e exploração da imaginação, como a pintura e o desenho, também são realizadas. Ademais, periodicamente são realizadas oficinas de artesanato, passeios e comemorações com dinamização de brincadeiras, premiações para o encerramento do semestre letivo e apresentação de peças teatrais. Como aproveitamento da estrutura histórica e turística de Ouro Preto e região, as crianças são convidadas a um passeio de trem Maria Fumaça que vai de Ouro Preto a Mariana. As crianças vão de trem até a cidade de Mariana, onde brincaram no parque educativo que há na estação, e depois retornaram a Ouro Preto, ouvindo instruções sobre o caminho da estrada de ferro.

Ao longo de seus 16 anos de existência, a biblioteca tornou-se imprescindível para a comunidade de Saramenha de Cima. Como consequência, foi criado um comitê gestor a partir de 2013, composto pelos representantes da Universidade Federal de Ouro Preto - UFOP, da paróquia local e da associação de moradores da comunidade. Esse conselho tem como objetivo estabelecer maior integração dos envolvidos no projeto, possibilitando resultados eficientes e que atendam as demandas reais da comunidade que abriga o projeto. Para tanto, são realizadas reuniões periódicas nas quais são discutidas novas atividades e sugestões de eventos.

Dessa forma, após descrição da visão teórico-metodológica da biblioteca comunitária de Saramenha de Cima, o 
presente artigo objetiva demonstrar a influência da atuação do projeto para a sociedade local, avaliando o impacto causado no bairro, na vida dos frequentadores da biblioteca e na visão de mundo dos alunos extensionistas da UFOP.

\section{Metodologia}

O presente estudo visa avaliar, a influência da biblioteca comunitária de Saramenha de Cima na comunidade local. Inicialmente buscou-se uma pesquisa qualitativa sobre as mudanças geradas no dia a dia dos moradores do bairro a partir do início do projeto, observando os principais pontos de transformação gerados na mentalidade da população local, na rotina dos mesmos e no desenvolvimento social através da educação. Pereira et al. (2018) evidenciam o estudo qualitativo como aquele que ocorre no ambiente natural, com a coleta de dados, preferencialmente descritivos, realizada de forma direta tendendo a seguir processos indutivos nos quais a concepção das pessoas em relação as coisas e a sua vida são pontos relevantes da pesquisa.

De acordo com Godoy (1995), a pesquisa qualitativa se faz reconhecida na busca do estudo das relações sociais construídas a partir de fenômenos que envolvem seres humanos. Assim, a perspectiva das pessoas inseridas em tais situações, caracterizadas no presente estudo pelos participantes da biblioteca comunitária e membros da comunidade local, seja considerada como objeto de estudo para melhor entendimento da dinâmica do projeto e seus benefícios.

A segunda abordagem do estudo consistiu na avaliação estatística do rendimento escolar das crianças da comunidade de Saramenha de Cima após o início do projeto da Biblioteca comunitária. Para isso, de forma semelhante a Queiroz et al. (2020), foi realizada a avaliação do Índice de Desenvolvimento da Educação Básica (Ideb) e os resultados da Prova Brasil para a escola René Gianneti, principal instituição de ensino do bairro de Saramenha de Cima. Considerando a escola como receptora de todas as crianças atendidas pela biblioteca comunitária, o índice de rendimento dos alunos permite mensurar o nível de conhecimento e desenvolvimento educacional dos mesmos ao longo dos anos de atuação do projeto extensionista. Foram avaliados os resultados dos anos de 2007, 2009, 2017 e 2019, comparando com as médias obtidas pelas escolas da cidade de Ouro Preto, do Estado de Minas Gerais e em relação à média nacional.

Por fim, o desenvolvimento promovido pela biblioteca comunitária aos alunos extensionistas da UFOP, atuantes no projeto foi avaliado. A partir da investigação qualitativa, buscou-se mensurar, a partir do ponto de vista do extensionistas, a importância da participação na biblioteca comunitária no crescimento dos graduandos, tanto no âmbito acadêmico como, principalmente, no caráter pessoal dos mesmos. Foi avaliado o aprendizado proporcionado pela experiência em um projeto extraclasse, em um universo consideravelmente diferente do encontrado nas universidades e no contato com pessoas de todas as classes sociais, níveis de conhecimento e vivências únicas.

\section{Resultados e Discussão}

A atuação da Biblioteca Comunitária em Saramenha promoveu, ao longo destes 15 anos de existência, melhorias consideráveis à população atendida e aos membros do projeto. Após a implantação da biblioteca, o local se tornou um ponto de apoio aos moradores do bairro, sendo fonte de desenvolvimento pessoal e cultural, de aprimoramento pedagógico e lazer.

Esse cenário, aliado ao fato de a biblioteca ser parte de um projeto conjunto de diferentes setores da comunidade, associado à UFOP, ao IFMG e às instituições do próprio bairro, gerou na população local um sentimento de pertencimento ao projeto. A consequente identificação com a biblioteca faz com que os moradores do bairro de Saramenha mantenham o local ativo. É nítido que a biblioteca se tornou parte da comunidade, de modo que o projeto e seus membros são apoiados pela população, fator indispensável para a manutenção de qualquer atividade comunitária.

A atuação da Biblioteca Comunitária de Saramenha tornou-se um ponto importante de socialização do bairro, onde as crianças têm acesso à informação, integração, entretenimento e cultura. A realização de atividades extraclasse, como passeios e 
gincanas, proporcionam às crianças novas vivências e, consequentemente, desenvolvem nelas maior conhecimento de mundo de uma maneira diferente daquela proporcionada nas salas de aula, gerando novas formas de raciocínio e concepções.

\subsection{A atuação da biblioteca no rendimento escolar das crianças do bairro}

Ao longo dos anos de atuação, foi possível notar que a Biblioteca Comunitária do bairro de Saramenha, conjuntamente a outros agentes apoiadores, colaborou para a evolução do aprendizado dos estudantes da região. Os resultados do Ideb da escola René Gianneti demonstram um elevado nível de conhecimento e desenvolvimento educacional dos alunos. Comparando com as médias municipais, estaduais e nacionais (Figura 1), percebe-se que a escola apresenta índices crescentes ao longo dos anos de atuação do projeto, além de resultados sempre superiores às médias das outras instituições da cidade de Ouro Preto e resultados ainda melhores à média nacional, corroborando com o entendimento da população, dos alunos e dos educadores da cidade que constantemente evidenciam a escola local como uma das referências em ensino de qualidade na região.

Figura 1: Médias municipais, estaduais, nacionais e da E.M. René Gianneti para o Ideb.

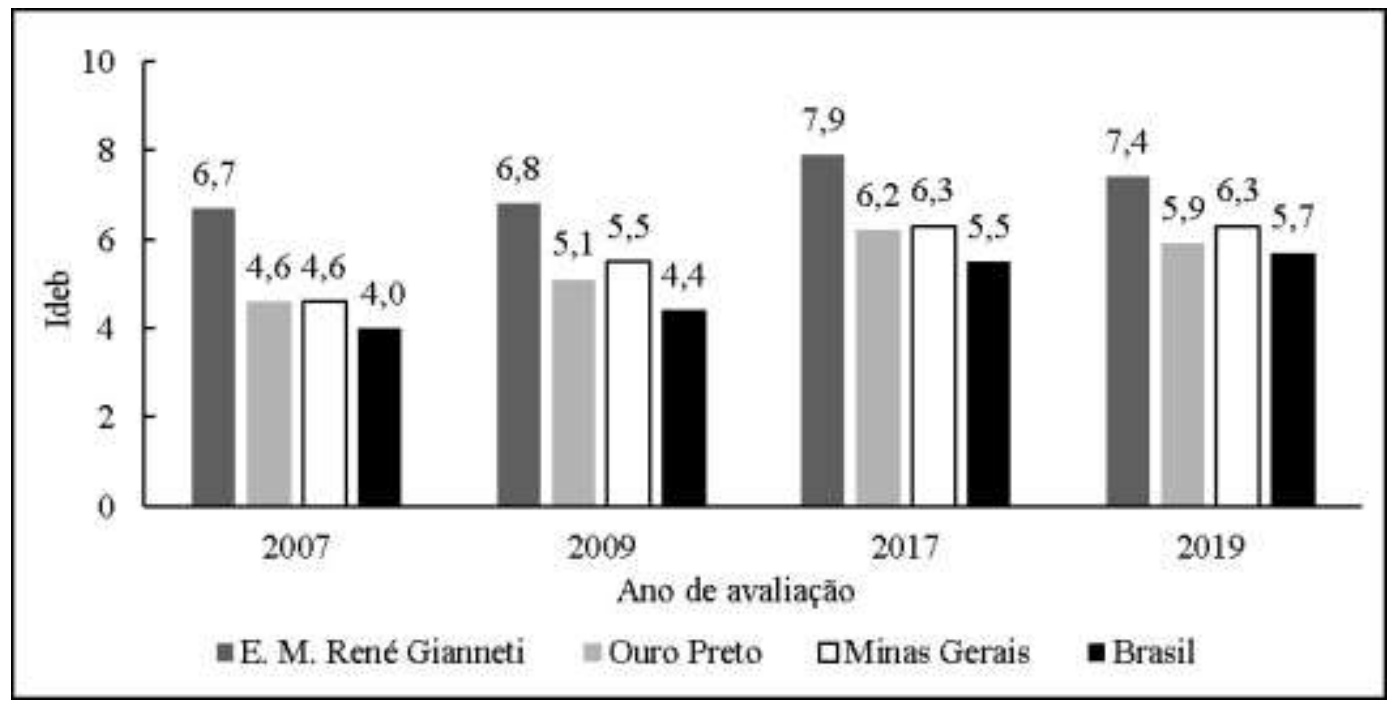

Fonte: Adaptado de Inep (2020).

Além dos resultados da avaliação do Ideb, a média de aprovação dos alunos da escola René Gianneti no último ano foi de aproximadamente 94\%. Esse resultado, associado aos elevados índices de proficiência dos alunos (Figura 2) também corrobora a máxima de um ensino de qualidade. Tal fato permite concluir que as atividades exercidas pela Biblioteca Comunitária, como a prática de reforço escolar, oficinas de leitura e o auxílio nas lições de casa influenciaram positivamente no rendimento das crianças, visto que a biblioteca atua diretamente no processo de aprendizagem e no desenvolvimento pedagógico dos alunos. 
Figura 2: Médias municipais, estaduais, nacionais e da E.M. René Gianneti de proficiência escolar.

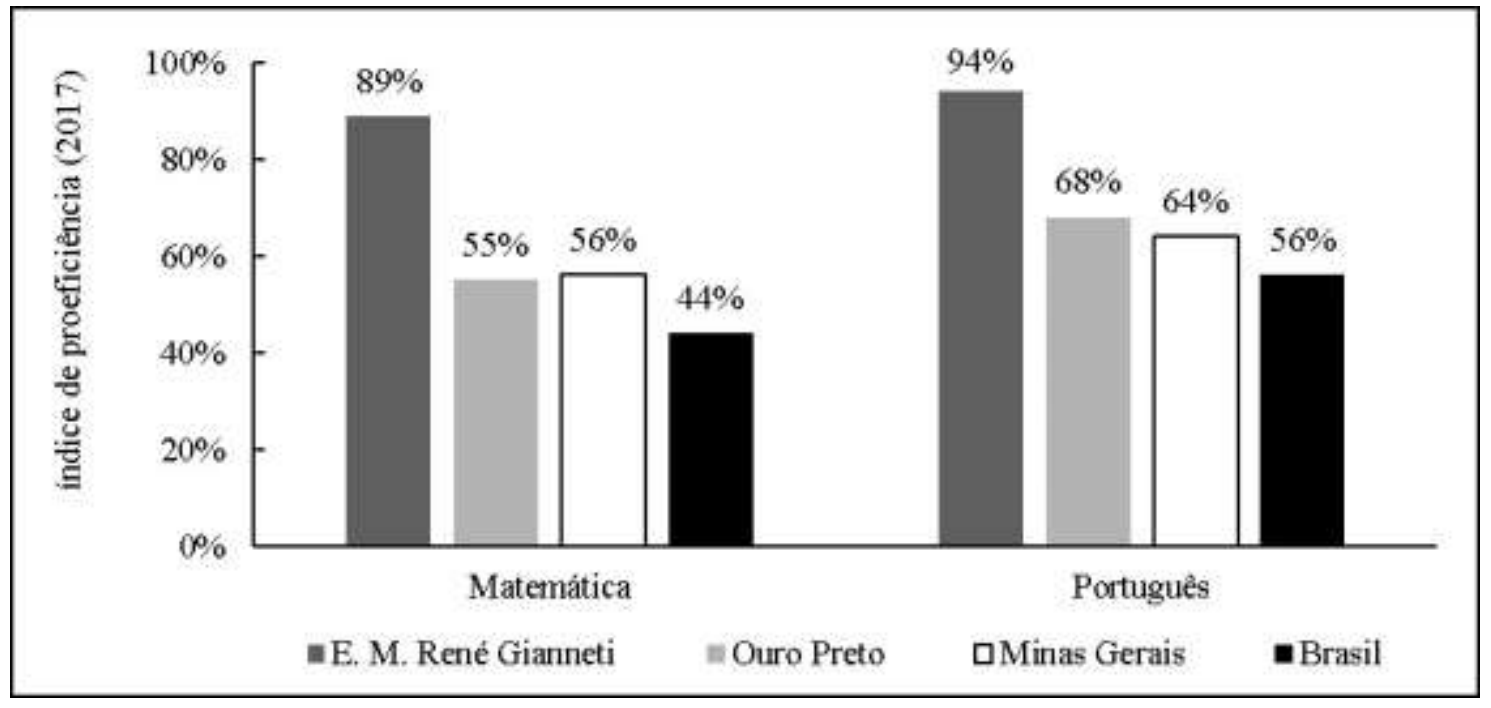

Fonte: Adaptado de Inep (2018).

\subsection{Dos extensionistas da biblioteca}

Durante os 15 anos de existência, a Biblioteca Comunitária de Saramenha promoveu a integração de vários alunos extensionistas da UFOP e do IFMG nas atividades do projeto, muitos deles moradores do bairro. Até o presente ano a biblioteca contou com a participação de pelo menos 28 alunos dos cursos de História, Artes, Letras, Museologia, Nutrição, Engenharia Civil, Ciências e Tecnologia dos Alimentos, Direito, Serviço Social, Educação Física, Engenharia de Minas e Engenharia Metalúrgica.

A participação desses alunos promove uma troca de conhecimentos muito benéfica ao projeto e aos frequentadores. A presença de extensionistas de variados cursos, oriundos de diferentes universos de atuação e com vivências únicas garante uma pluralidade de conceitos que agrega valores à biblioteca, possibilitando o desenvolvimento de diferentes ideias, ações e métodos de abordagem.

Ao longo do período de funcionamento, a atuação da Biblioteca Comunitária de Saramenha rendeu a publicação de quatro artigos em congressos nacionais e um artigo em congresso internacional, além de um capítulo de livro, todos escritos com a participação dos alunos extensionistas. Tal fato reitera a boa condução dos trabalhos na biblioteca, visto que essas publicações representam, de certa forma, o reconhecimento do projeto, da ação dos extensionistas e da importância da extensão universitária.

Ao mesmo tempo, a participação nas atividades da biblioteca permite aos extensionistas um notório desenvolvimento pessoal, desenvolvendo habilidades transversais que, como evidenciam Souza e Campos (2019) se tornaram essenciais para o sucesso profissional dos estudantes. Durante os trabalhos na biblioteca os participantes do projeto atuam em contato com uma realidade diferente da que estão acostumados na universidade, convivendo com diferentes grupos de pessoas e atividades. Dessa forma, assim como descrito por Kuhn, Siqueira e Gomes (2019), os extensionistas aprimoram características como o relacionamento interpessoal, a didática, a gestão de pessoas e de projetos, sua capacidade de reflexão, crítica e, principalmente, a empatia e a concepção da importância dos valores humanos, tão essenciais quanto os conhecimentos técnicos fornecidos nos cursos de graduação.

Além disso, semelhante ao evidenciado por Scheidemantel et al. (2018), a parceria entre a UFOP e a Biblioteca Comunitária aproxima os moradores do bairro da instituição de ensino, possibilitando a troca de valores entre a universidade e a população local, promovendo o desenvolvimento mútuo da comunidade e fortalecimento da extensão universitária como um todo. A presença de alunos e professores da universidade no dia a dia do projeto traz aos frequentadores da biblioteca o 
universo acadêmico de forma mais clara, prática e atuante. Assim, as pessoas do bairro compreendem melhor a atuação e os valores da universidade para a sociedade, fazendo com que as crianças se inspirem nos alunos extensionistas e, então, motivem se a continuar dedicando aos estudos para, no futuro, ingressarem em uma universidade, como é percebido pela presença, cada vez maior, de alunos oriundos do bairro Saramenha em cursos da UFOP e de outras instituições de ensino.

\section{Conclusão}

A Biblioteca Comunitária de Saramenha de Cima tornou-se ponto importante de apoio social e pedagógico à população do bairro. O projeto é atualmente fonte fundamental de acesso à informação, de democratização do conhecimento, de integração da comunidade e de promoção cultural no bairro Saramenha de Cima. A participação direta de membros da comunidade na gestão do projeto, associada à realização de diversas ações de apoio pedagógico, oficinas, gincanas e outras atividades extraclasse, proporciona aos moradores locais um forte sentimento de pertencimento à biblioteca, caracterizando o local, genuinamente, como uma Biblioteca Comunitária. Os trabalhos realizados pela biblioteca colaboraram para a melhoria da qualidade do ensino do bairro, observada a alta nos índices educacionais da escola local, alcançando resultados de proficiência dos alunos e do Índice de Desenvolvimento do Ensino Básico (Ideb) superiores à média nacional, estadual e municipal.

Percebeu-se, também, a importância do projeto de extensão para os alunos da UFOP e do IFMG atuantes na Biblioteca Comunitária, seja para o desenvolvimento pessoal, acadêmico ou social dos mesmos. Ao longo desses anos de atuação, o projeto contou com a participação de dezenas de extensionistas de diversos cursos técnicos e superiores, promovendo, com isso, uma troca de experiências entre os envolvidos e as crianças da biblioteca, agregando um valor imensurável ao trabalho realizado. A parceria entre os alunos extensionistas e o projeto da Biblioteca Comunitária vem produzindo bons resultados, como a publicação de artigos em congressos, prêmios internacionais e capítulo de livro, além da presença cada vez maior de ex participantes do projeto em instituições de ensino, especialmente na UFOP.

Por fim, sugere-se a continuidade de estudos referentes a instituições comunitárias de apoio social, evidenciando cada vez mais o trabalho de tais centros educacionais, sociais e culturais. A avaliação de diferentes projetos e suas metodologias, assim como as diferentes mudanças promovidas nas comunidades em cada estudo de caso permitirão uma discussão rica e importante sobre a importância dos mesmos, dando visibilidade e incentivando o surgimento de novos projetos comunitários e maior apoio aos já existentes.

\section{Agradecimentos}

Os autores agradecem à UFOP, ao CNPq e à Fundação Gorceix pelo apoio na realização deste trabalho.

\section{Referências}

Almeida Júnior, O. F. (1993). Bibliotecas públicas e alternativas. Revista brasileira de biblioteconomia e documentação, 26 (1-2), 115-127. http://www3.eca.usp.br/sites/default/files/form/biblioteca/acervo/producao-academica/000866735.pdf

Batel, T. H., \& Bogado, A. M. (2003, novembro). Tertúlia Literária Dialógica: Superando o preconceito pela idade. Anais do $1^{o}$ Congresso Regional de Educação de Pessoas Adultas (CREPA), São Carlos, Brasil.

Batista, N. L., Feltrin, T., Cassol, M. S., Roubuste, L. D. S., \& Becker, E. L. S. (2019). Reflexões sobre as tecnologias de informação e comunicação na escola pública por um viés autobiográfico. Research, Society and Development, 8(6), e13861029. https://doi.org/10.33448/rsd-v8i6.1029

Darós, L. L., \& Pereira, A. S. (2009, July). Análise das normas brasileiras de contabilidade aplicadas ao setor público - NBCASP: Mudanças e desafios para a contabilidade pública. Anais do $9^{\circ}$ Congresso USP Controladoria e Contabilidade, São Paulo, Brasil.

Dewey, J. (1940). My pedagogic creed. In Education Today (1st ed., Vol. 1, pp. 8-18). G.P.Putnam’s Sons.

Fernandez, C., Machado, E., \& Rosa, E. (2018). O Brasil que lê: bibliotecas comunitárias e resistência cultural na formação de leitores (1st ed., Vol. 1). RNBC. https://rnbc.org.br/wp-content/uploads/2020/01/Ebook-OBrasilquele.pdf 
Research, Society and Development, v. 10, n. 16, e242101623664, 2021

(CC BY 4.0) | ISSN 2525-3409 | DOI: http://dx.doi.org/10.33448/rsd-v10i16.23664

Flusser, V. (1980). Uma biblioteca verdadeiramente pública. Revista Da Escola de Biblioteconomia Da UFMG, 9(2), 131-138. https://periodicos.ufmg.br/index.php/reb/article/download/36361/28454/109432

Fórum de Pró-Reitores das Instituições Públicas de Educação Superior Brasileiras (FORPROEX). (2012). Política Nacional de Extensão Universitária. Imprensa Universitária.

Freire, P. (1989). A importância do ato de ler (23a ed.) (p.33). Cortez.

Godoy, E.V., \& Santos, V.de M. (1995). Um olhar sobre a Cultura. Educação em Revista. 30. https://www.scielo.br/j/edur/a/g9PftWn8KMYfNPBs7TLfC8D/?format=pdf\&lang=pt

Instituto Nacional de Estudos e Pesquisas Educacionais Anísio Teixeira - Inep. (2020, setembro 15). Índice de Desenvolvimento da Educação Básica (Ideb). Recuperado 15-06-21, de http://ideb.inep.gov.br/.

Instituto Nacional de Estudos e Pesquisas Educacionais Anísio Teixeira - Inep. (2018, outubro 01). Prova Brasil - Avaliação do Rendimento Escolar. http://sistemasprovabrasil.inep.gov.br/provaBrasilResultados/.

Kuhn, C. E. S., Siqueira, F. R. P. S. D., \& Gomes, A. C. F. (2019). Extensão universitária e desenvolvimento do pensamento crítico de estudantes de engenharia de minas e geologia. Research, Society and Development, 8(3), e3283730. https://doi.org/10.33448/rsd-v8i3.730

Machado, E. C., \& Vergueiro, W. (2010). Bibliotecas comunitárias como prática social no Brasil. CRB8 Digital, 3(1), 3-11. https://brapci.inf.br/index.php/res/download/46481

Montessori, M. (2003). Para educar o potencial humano (2a ed.) (p. 20). Papirus.

Pereira, A.S., Shitsuka, D. M., Parreira, F. J., \& Shitsuka, R. (2018b). Metodologia da pesquisa científica. Santa Maria, UFSM.

Pires, T., Freire, C., Silva, F. G., Silva, F. G., \& Pereira, C. A. (2016). Espaço social destinado ao exercício e à difusão da leitura, cultura e cidadania. Além Dos Muros Da Universidade, 1(1), 15-24. https://periodicos.ufop.br/alemur/article/view/304

Queiroz, J. P. B. D., Bezerra Neto, F. D. C., Caiana, C. R. A., \& Maracajá, P. B. (2020). O direito fundamental à educação: uma análise das disposições constitucionais em contraponto com a realidade fática. Research, Society and Development, 9(5), e145953310. https://doi.org/10.33448/rsd-v9i5.3310

Rodrigues, A. L. L., Costa, C. L. N. do A., Prata, M. S., Batalha, T. B. S., \& Passos Neto, I. de F. (2013). Contribuições da extensão universitária na sociedade. Caderno De Graduação - Ciências Humanas E Sociais - UNIT - SERGIPE, 1(2), 141-148. https://periodicos.set.edu.br/cadernohumanas/article/view/494.

Scheidemantel, S. E., KLEIN, R., \& TEIXEIRA, L. I. (2004, setembro). A Importância da Extensão Universitária: o Projeto Construir. Anais do $2^{\circ}$ Congresso Brasileiro de Extensão Universitária, Belo Horizonte, Brasil.

Silva, L., \& Sousa, M. P. B. S. (2010). Bibliotecas Públicas e Comunitárias: Alternativas de Desenvolvimento Social. Interface, 7(2), 9-18. https://ojs.ccsa.ufrn.br/index.php/interface/article/view/133/134

Souza, A. S., \& Campos, L. B. P. (2019). Habilidades transversais de engenheiros em formação: o papel de projetos de extensão. Research, Society and Development, 8(4), e684712. https://doi.org/10.33448/rsd-v7i4.712

Suaiden, E. (1995). Biblioteca pública e a informação à comunidade (1 ed., Vol. 1). Global.

Targino, M. G. (1991). Biblioteconomia, informação e cidadania. Revista Escola de Biblioteconomia Da UFMG, Belo Horizonte, 20(2), 149-160. https://brapci.inf.br/index.php/res/v/75418 